\title{
A Quest on the Role of Aesthetics in Enhancing Functionality of Urban Planning
}

\author{
Hourakhsh Ahmad Nia ${ }^{1, *}$, Fashuyi Olugbenga ${ }^{2}$ \\ ${ }^{1}$ Department of Architecture, Alanya Hamdullah Emin Pasa University, Alanya, Antalya, Turkey \\ ${ }^{2}$ Federal University of Technology Akure Ondo State Nigeria, Nigeria
}

Received July 22, 2020; Revised September 13, 2020; Accepted September 19, 2020

\begin{abstract}
Cite This Paper in the following Citation Styles
(a): [1] Hourakhsh Ahmad Nia, Fashuyi Olugbenga , "A Quest on the Role of Aesthetics in Enhancing Functionality of Urban Planning," Civil Engineering and Architecture, Vol. 8, No. 5, pp. 873 - 879, 2020. DOI: 10.13189/cea.2020.080514.
\end{abstract}

(b): Hourakhsh Ahmad Nia, Fashuyi Olugbenga (2020). A Quest on the Role of Aesthetics in Enhancing Functionality of Urban Planning. Civil Engineering and Architecture, 8(5), 873- 879. DOI: 10.13189/cea.2020.080514.

Copyright $\bigcirc 2020$ by authors, all rights reserved. Authors agree that this article remains permanently open access under the terms of the Creative Commons Attribution License 4.0 International License

\begin{abstract}
In view of the dramatic increase in the population of world cities, the necessities of aesthetic urban planning have increased. Addressing the aesthetics problems of urban spaces implies working with new models of aesthetic cities for developing comprehensive urban planning. This study highlights the importance of the consideration of urban aesthetics in the urban planning process using the qualitative grounded theory study as the main methodology. The study further showed the need for planners to consider economic and social outputs in planning considerations. The study contributes that the planning process should be tailored to implement aesthetic inherited planning into urban planning management.
\end{abstract}

Keywords Urban Aesthetics, Urban Planning, Qualitative Grounded Theory, Pillars of Urban Aesthetic Planning

\section{Introduction}

Current estimates show that more than $50 \%$ of the world's population resides in urban areas. The population may also rise to $70 \%$ by 2050 [1]. From the aesthetic point of view, it can be observed that urban planners provide some of the worst as well as some of the best form of urban spatial configuration. Indeed, urban aesthetics is a reflection of poor or wholesome urban planning. On the one hand, the challenges posed by poor environmental judgment enhance socioeconomic disparities and stress and are also related with urban well-being and health. On the other hand, urban aesthetics itself is a reflection of the quality of life as well as the socio economic, cultural and physical aspects of urban design collectively considered. An umpteenth record of research across disciplines including urban and aesthetics studies has been documented on the paths associating urban planning and aesthetics [2, 3, 4]. The purview of 'aesthetics' within the Town Planning discuss extends no further than the reference to the external design of a building. And, it has remained a tradition that many architects would normally argue that the exercise of aesthetic control on development proposals should not be the responsibility of planning bodies and that owing to the subjective nuances involved, such matters should be the exclusive privilege of architects and clients alone. According to the Planning policy guidance (1990) good design which is compatible with character and scale with its surroundings should be the goal of clients and professionals involved in the development process. The guide further asserted that the obligation to reject poor designs especially those that are conspicuously out of harmony and scale with their surroundings lies with the clients, designers and planning authorities. Authorities should recognize that aesthetic judgments are in themselves subjective and as a result factor the applicant's aesthetic taste in their decision for approving or rejecting proposals [5].

Thus, it can be stated that the proper use of space at any time is determined by insightful aesthetic judgment. Such 
judgment is related to the aesthetic theories which are fundamental in making sense out of the experiences and perceptions regarding the daily use of space. Put differently, aesthetic theories define the paths to aesthetic planning. Aesthetic planning approach is more successful and context-oriented when beneficial implements to discuss the values of urban space are developed especially within pragmatist and phenomenological philosophy.

Planning theory, the seedbed for aesthetic planning [6], is usually perceived in the context of the planning process and that it relates to the theories of planning and objects of planning. It can be observed that while contemporary planning leans to the procedural theories of planning, theories of urban design and architecture have endured substantially a system of subjective planning. All planned decisions either reached objectively methodical or systemically subjective, often have unplanned consequences. It is stressed that these consequences arose as a result of loop-holes in the basis upon which the decisions were reached and formulated [7].

The strength of the planning theory lies in its ability to reach goal decisions and evaluate alternative options. The most vivid example of these is in the putting forward of a set of alternatives and assessing them quantitatively and scientifically. However, these statistical assessments are incapable of capturing the subjective desires that underpin real-life situations.

Besides, strong aesthetic considerations are precluded in contemporary planning thoughts because of its methodical stance. From the pragmatist perspective where products and the processes that led to it demonstrate an ensemble, aestheticizing of the urban space is tantamount to urban space development [5]. In addition, the fact that architecture and urban design remains a vital part of planning underscores the role of the theory of aesthetics in urban planning. Hence, the lack of aesthetic view-points jeopardizes urban planning theories. Therefore, this study asserts that the aesthetic concern of the urban environment is of immense significance to urban planning professionals.

A paradigm shift in planning in the 1960s situated it apart into two formal lines of thoughts which were the view that planning is a pedagogical approach to reaching goals and a theory-based system view of planning [7]. The systems view is usually a statistical approach and typically anti-aesthetic although the line of "environmental aesthetics" in view in this study, could on the equilibrium has a bearing on the systems view of a public urban space. As such, aesthetics of a public urban space has become relevant in cities with static urban-imagery, or picturesque townscapes, as well as with social-life of the people, their environments, and the processes of urbanism [7].

Thus, highlighting the importance of urban aesthetic from phenomenological point of view is also germane to this study. Despite these, aesthetics remains largely unconsidered in urban environmental planning. Some of the reasons for this relate to the ambiguity in the definition of the urban environment itself. This is elucidated in the contentions that arise in demonstrating the urban environment as partly objects of art, and admitting that aesthetics as a term exclusively pertinent to art. On the other hand, the duality of the designer and urban planner, as organizer along with enabler and controller seems to assist enhancing "aesthetics" in urban planning programmes.

\section{Material and Methods}

\subsection{Urban Aesthetics}

It is a point of fact that urban aesthetic is an irreplaceable tool for promoting city idiosyncrasy identification and urban dynamics [8]. The assessment of what constitutes beauty in a city is beyond architectural characters, traffic controls and the noise effects, building styles, but historical and social features as well. Along these lines, on one hand, it has been shown that an increase in the aesthetic qualities of cities enhances its appreciation while on the other, studies have shown that "appreciation" in itself is exacting to conceptualize, nebulous and difficult to justify. The quest to unravel "what it means to appreciate a city" is one of the most profound discussions in urban aesthetic design. Berleant and Carlson [9] asserted that "...the aesthetics of the city is an aesthetic of engagement". The duo implied that the aesthetic of urban settings works by observer's active involvement and participation to impact on space.

Urban spaces with delightful aesthetics deliver hedonic happiness to participants via relaxation, observation and reflection [10]. In view of this, aesthetic design needs have become imperative in urban environments. Realizing the mutuality of engagement between human needs and the aesthetics of the environment in urban settings, Stamps [11] made a case for further research on the quality of the perceived environment.

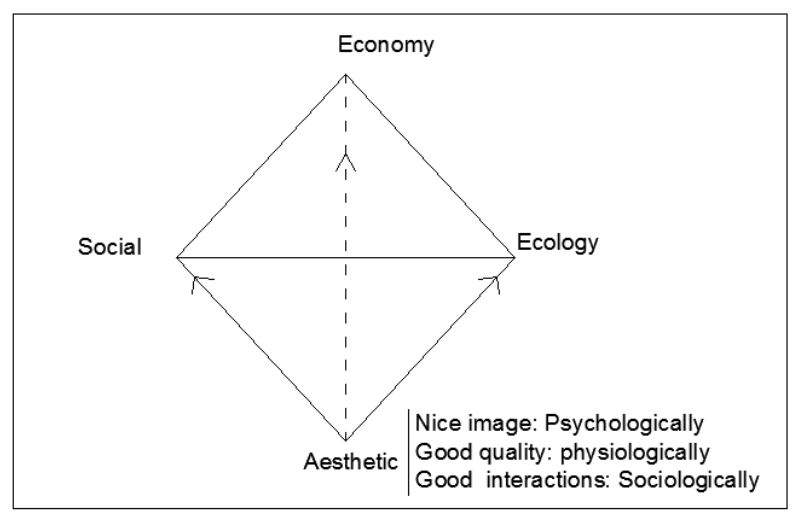

Urban environment

Figure 1. Aesthetic and the complementary paradigm of sustainability 
Tiesdell \& Carmona [12] laid further emphasis on the significance of aesthetics as a dimension of urban design in the design process. Other factors such as political, social, economic and legal nature are still required despite complementing the urban design with aesthetic efforts. It can therefore be put forward that aesthetic quality in urban environment is a component of sustainability alongside social, economic, and ecologic aims, which are other components of sustainable development. This assumption precludes our worldview of aesthetics as being related to external visual quality alone; but that the concept goes beyond and should be observed through a more comprehensive framework that factored other dimensions of urban design (See Figure 1).

The significance of these studies could not be overstated. For one reason, it is significant for the human physiologically and psychologically comfort. For the second, it is needful for solving associated problems linked to urban aesthetics. This may include such concepts as ugliness and visual clutter which are notorious for minimizing environmental hedonism. Thus, aesthetic value of spaces is associated with user's assessment of the spaces. Observers appraise their evaluation of a place positively or negatively depending on the beauty or ugliness of the place [13].

There are three main types of urban aesthetic considerations during the planning process. These are formal aesthetic, symbolic aesthetic and sensory aesthetic [14]. Maturity in planning requires experience to seethe through these factors.

a). Formal Aesthetic: This involves appreciating structures and shapes in the environment for their own sake. This aesthetic paradigm views the geometric quality of the environment as the dominant or important factor.

b). Symbolic Aesthetic: This is concerned with pleasure enhancing meanings associated with environmentally derived patterns. It has to do with feelingly experienced pleasure as a result of the peculiarities or specific landscape of the built environment. The built environment is a symbolic message; acknowledging this, either consciously or subconsciously is related to people's feelings and attitudes towards the environment and themselves.

c). Sensory Aesthetic: This is a significant aesthetic especially for relating people's responses to the environment. Several authors [15] are of the opinion that when urban designers and architects emphasize formal aesthetic, the symbolic meanings of the built environment become legible. Therefore, it is obvious that the combination of these considerations is required to achieve the aesthetically integrated approach to urban planning.

\subsection{Urban Planning}

Initially, urban planning emerged as the practical way of responding to the amorphous environment of the early nineteenth-century prewar cities but afterwards developed to an intellectual occupation beyond physical design. Planner's primary focus of the initial response was based on the managerial, political and social aspects of the built environment and in doing so largely ignored its physical qualities [16]. The resulting urban declension inflamed contentious remarks amongst landscape architects, architects and planners especially after the 1960s. Ironically, through these contentions, the quest for the aesthetic quality in public urban spaces gained a further foothold. It reinforces the fact beyond physical consideration it focuses on the social and psychological constructs of the design process. Though "urban planning" acknowledged the significance of "urban design," continuing discussion among urban design and planning has been viewed in two broad areas: scale and emphasis on design.

By the late 1850s, city beautification movement under the leadership of Ebenezer Howard, Frederick Law Olmsted and Daniel Burnham was initiated as recourse to the inhospitable and unpleasant American cities. These architects felt that aesthetic transformation for pleasant environments has become imperative in cities [17]. The significance of this operation lies in the maxim that an orderly environment begets a good society. While mismatched and unwholesome cities result in crime and vandalism, good and beautiful environments can enhance the social life and aspects of proper moral behaviors. In 1890s Camillo Sitte [9], reechoed the strong impacts of the physical environments on the human soul. He went further to say that the city should be a happy and secure habitat for dwellers. Thus, the city by purpose should go beyond the mere functionality of activity areas to the legibility of artistic pattern. This is imperative to the city planning profession. The 1950s to 1960s was an era of a paradigm shift when against the theory of physical determinism. Theoreticians began to argue in favor of the importance of the aesthetic of the built environment on the social life of the people. They emphasized the need for planners to realize the extent that social forces influence the aesthetics of the built environment since the goal of urban planning is to design and maintain a salubrious environment based on aesthetics and good design. Indeed, a significant amount of extant master plans suggest the totalitarian and utopian characters of physical determinism's approach to urban planning, in which case architecture and planning became instruments to destroy disorder and chaotic urban spaces. Overall, critical examination of planning is expedient in rethinking the praxis of the profession especially in terms of aesthetics and quality of the environment. 


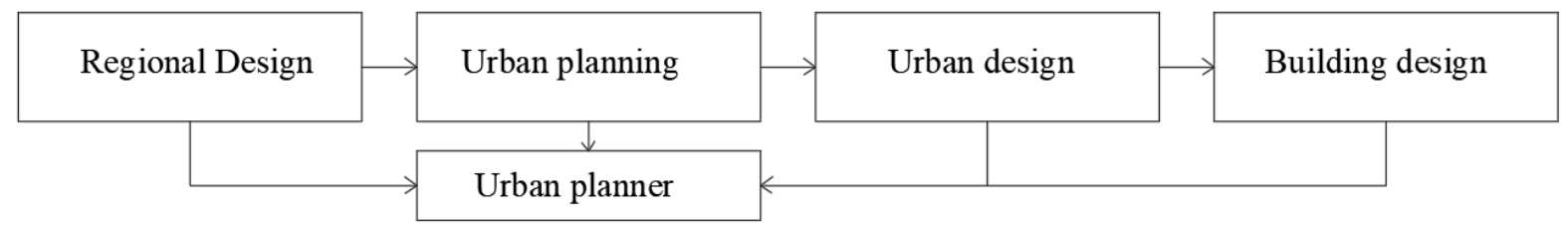

Figure 2. Urban planner and the required knowledge of Space Organization

Regarding roles and responsibilities, planners have more to do in the anesthetization of urban spaces than urban designers and this fact denotes the significance of urban planning in the aesthetics of future cities. Thus, contributions and suggestions of planners on the effects of space organization on the aesthetic value of the city become very imperative. The process of aesthetic development of urban spaces is the link between the higher-level decisions to the levels below; such as from regional to town planning. Hence, planners should have a comprehensive overview of the fundamentals of aesthetic planning and the main stages of the city planning process that lead to the aesthetics of the urban design.

There are two main approaches to urban planning:

The classical approach "the blueprint view of planning": The approach which emerged in architecture was developed as a response to city aesthetics while considering public health. Usually, the planner is a visionary who conceives a futuristic model for a specific area. He is a virtuoso employing his acumen on the society to manipulate spaces in an attempt to provide hedonic environments regardless of the society related to the place. This approach to planning rest on the philosophical realization that man is the measure of all things and can provide solutions to his problems [18].

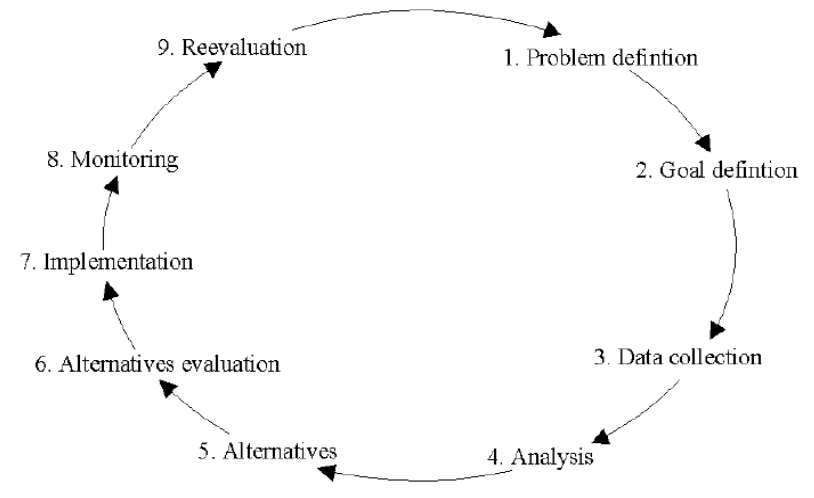

Figure 3. The planning processes

The systematic view of planning: This approach to planning can be succinctly stated as 'survey - analysis plan'. The pioneer was Sir Patrick Geddes (1854-1932) who is attributed to have developed the principles of modern town planning. The tenets of his approach are the use of scientific methods as evaluative options, the assertion of comprehensiveness and the application of "instrumental rationality". Thus, the systematic view approach is out-modestly pedantic for which it is denoted "the rational approach" [19]. Figure 3 is a figurative narrative of the systematic approach to planning which has been adapted in umpteenth varieties in many countries (Figure 3).

\subsubsection{Approaches to Aesthetic Urban Planning}

The aesthetic concept is not new in urban design and planning. Traditional theories of urban design focus on the physicality of the built environment alone. With this realization, planners figure out other theories to fit planning into realms beyond mere physicality. "Figure-Ground" theory, for instance, underscores the usefulness of the open space and interconnectedness of solids and voids in the urban space, whilst the undergirding of the "Linkage Theory" relates to urban thoroughfares and the streets. The "Place Theory", puts emphasis on the relationships between the social aspects of the space and human activities [20,21,12]. In all of these approaches, explicit visions on urban sustainability were hardly demonstrated. Hence, more recent approaches, amongst which are Green Urbanism and New Urbanism, have elaborated on the impacts of social aspects of planning on the built environment. In practice, these planning distinctions do not exist. Despite all of these, a set of liveability and sustainability interventions (rather than branding reality) amenable to local nuances are more copious in cities. In each city, constraints and opportunities should be wholly addressed to reflect peculiar urban systems of environmental, social and economic life [22]. It has been observed that the system of transportation impacts the liveability of contemporary cities in real-life situations [23] and that social integration [24] and resource management enhances resilience and durability in cities [25]. In point of fact, the interactions between dwellers, infrastructure and transport networks are the undergirding of the micro-structure of sustainable cities [26]. In this way, aesthetic cities should integrate environmental, social and economic components into a systemic whole. Balancing the components requires an integrated decision-making process aimed at achieving urban design objectives.

It is also useful to reecho that Urban Planning is the foundational undergirding for all proposed urban development including housing. It considers the complex interplay between social (social amenities), institutional (capacity and policies/regulations) cultural (locally acceptable), environmental (resilient locations and healthy water/sanitation), financial (public and private resources), economic (close contiguity to informal/ formal 
employment chances), and physical components (infrastructure and land) in arriving at urban design solutions. Indeed, urban planning is a multi-sided process that requires consolidated preparations to achieve a balance between politics, spatial planning objectives and stakeholder's actual needs. Thus, an iterative process requiring a full range of stakeholders involved in decision-making and incorporating feedback often results in a promising urban design approach. Figure 5 illustrates the complexity of issues and sectors considered.

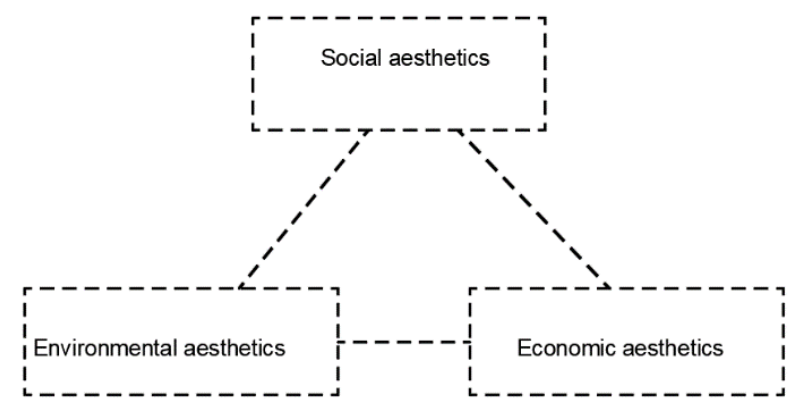

Figure 4. Three main pillars in aesthetic consideration in urban planning

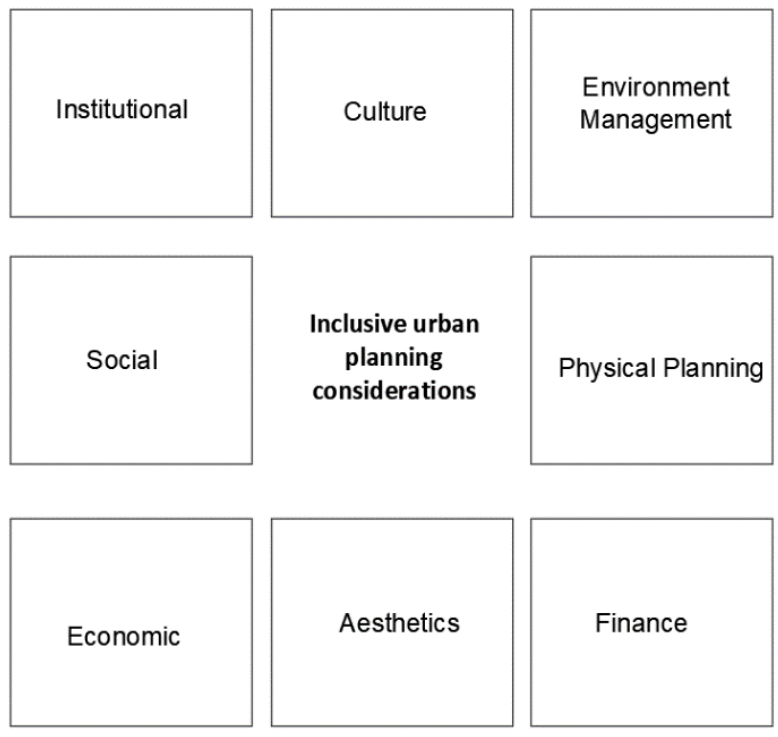

Figure 5. Sectors to be considered in Urban Planning process

\subsubsection{Collaborative Planning as Proposed Method of} Aesthetic Design

The theoretical discussion on planning, the objectives and aims reinforces the values already attributed to it. The realization of this discussion on planning has led to the existing "communicative turn" in planning theory [27]. "Communicative Planning Theory" is basically a theory of the praxis of the planning; interpreting and describing the planning profession. Khalee [28] observed that the theory goes further to point attention to what moral issues are involved in the profession. The seedbed that anchors the theory has been said to draw from Jiirgen Habermas's theory of communicative action although the extent of this is left for speculation [27, 29, 30]. Habermas, being a philosopher posits that rationality cannot solitary bring up “instrumental rationality' and that as a result, a rational debate of "values" is conceivable. Aestheticians have abstracted from Habermas's theory to demystify the role of aesthetics even though aesthetics is not the main anxiety in his theory. Despite of this, Habermas emphasized that aesthetic and art experiences exert a significant influence on modern society to enrich life-worlds. Habermas's aesthetics may offer the needed conceptual support for planning particularly the awareness of novel perspectives which may help enriching planning applications.

\section{Discussions}

\subsection{Modeling on Aesthetics in Urban Planning}

This involves the operationalization of aesthetic planning concepts for planning and it has been categorized into two according to its use. The uses are first, for the purpose of urban planning and second, for the utilization of planning program for aesthetic design of the urban space.

Urban planners need to consider aesthetics as the main environmental policies which require implementation in planning policies. In this regard, formal, symbolic and social considerations of aesthetic design need to be put together in such a way as to implement the principles of aesthetic design in the planning process. This view is consistent with earlier positions of this study that aside from environmental aspects of urban aesthetics, planners should reflect on the economic and social outputs of their planning considerations. Overall, it can be stated that the planning process should be utilized in such a way that aesthetic inherited planning can be impacted by urban planning management. The following model (Figure 6) represents the strategical thinking model for urban designers who need consideration during the urban planning process. 


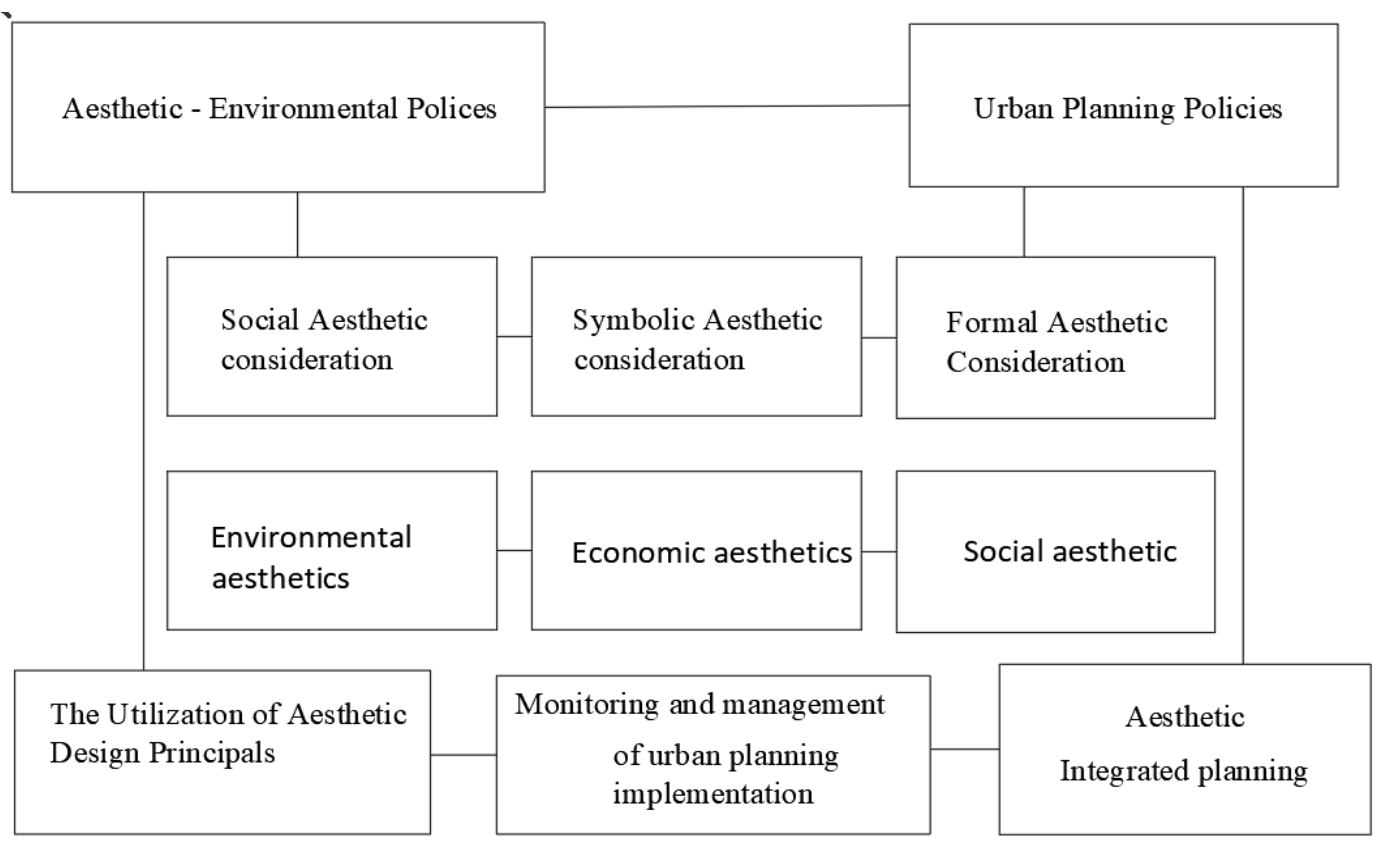

Figure 6. Strategical thinking model for urban Planners

\section{Conclusions}

Urban population explosion and the attendant increase in social and psychological problems reinforce the need for urban aesthetic planning by urban planners. The view that urban planning is a decision-making process independent of cities' subjective perception calls for alternatives. The alternative should be reinforced with pragmatist and phenomenological ideas to strengthen the aesthetic quality of urban space and to promote the urban planning process. The study revealed that the homogeneity of produced aesthetic in urban planning, broadly speaking, is non-confrontational and acceptable. The study also serves as a caveat for planning theorist to recognize the effects of monolithic cities on suitability. Hence, it is imperative for them to be engaged with image creation to foster creative planning. Realizing that images are innately political and are imbued with knowledge and power, implication and force makes this especially so. These notwithstanding, aesthetics concern goes beyond the purview of the built environment to the social and cultural construct and as a result, urban diversity can as well be examined as a cultural and social variety. Therefore, the urban space configuration should be a plan to accommodate social, environmental, and cultural nuances. Overall, comparing the traditional model of urban planning which indeed focuses mostly on the abilities of the urban designer to employ different knowledge from different disciplines for providing urban design solutions, it remained obvious that city planning leading to urban planning is an interconnected process. Doubtless, city planners need to have this knowledge - in architecture, landscape architecture and urban design -as well as in other fields so as to achieve increasing aesthetic value of prospective city planning. It has also been stated in this study that there are three main components to urban aesthetic considerations. From this perspective, this study highlights the need for economic and social considerations aside from aesthetics outputs in planning designs. Overall, it can be stated that the planning process should be utilized in such a way that urban planning management can influence aesthetic inherited planning to reach desired goals and objectives. Research on the methods for implementing aesthetic planning processes has remained largely unattended to and its therefore suggested for further studies.

\section{Acknowledgements}

This research did not receive any specific grant from funding agencies in the public, commercial, or not-for-profit sectors.

\section{Conflict of Interests}

The authors declare no conflict of interest.

\section{REFERENCES}

[1] United Nations, Department of Economic and Social Affairs. (2014). Population Division. World Urbanization Prospects: The 2014 Revision, CD-ROM Edition; United Nations, Department of Economic and Social Affairs, Population Division: New York, NY, USA.

[2] Wang, H., Newman, G., \& Wang, Z. (2019). Urban Planning as an Extension of War Planning: Journal of Contemporary 
Urban Affairs, 3(1), 1-12. Retrieved from https://doi.org/10.25034/ijcua.2018.4677

[3] Harvey, D. (1989) The Urban Experience, Blackwell, Oxford.

[4] Welsch, W. (1997). Undoing Aesthetics. London: Sage.

[5] Ratcliffe, J., Stubbs, M and Shepherd, M. (2004). Urban Planning and Real Estate Development. Second Edition. Spon Press.

[6] Wilson, W. H. (1996). The Glory, Destruction, and Meaning of the City Beautiful Movement, in S. Campbell and S. Fainstein (eds) Readings in Planning Theory, pp. 68-103. Oxford: Blackwell.

[7] Munasinghe, H. (2001). Aesthetics of Urban Space through Collaborative Urban Planning: Integrating Environmental Aesthetics with Communicative Theory of Planning. Built-Environment-Sri Lanka- 2 (1). http://doi.org/10.4038/ besl.v2i1.7629

[8] Sternberg, R. (1991). The urban aesthetic in comparative perspective. In: Environmental, Urban and Geographic Studies, pp. 70-79. Upper Montclair, NJ, Montclair State College.

[9] Sitte, C. (1889). City Planning According to Artistic Principles. (G. R. Collins, \& C. Collins, trans.). London: Phaidon Press.

[10] Philipp, R., Pond, K., Rees, G., and Bartram. J. (1999). The association of personal well-being with aesthetic quality and environmental values; p.93: In: Mobility and Health: From Hominid Migration to Mass Tourism. Abstracts book. European Conference on Travel Medicine, Venice, Italy, 25-27 March 1998; pp.196

[11] Stamps, A. E. (2000). Psychology and the aesthetics of the built environment. Dordrecht, The Netherlands: Kluwer Academic Publishers Group.

[12] Jacobs, J. (1961), The Death and Life of Great American Cities, Random House Inc, New York.

[13] Bell, P. A., Greene, T. C., Fisher, J. D., \& Baum, A. (2001). Environmental Psychology (5th ed.). New York: Harcourt.

[14] Lang, J. (1988). Environmental Aesthetics: Theory, Research and Applications. New York: Cambridge University Press.

[15] Tiesdell, S., \& Carmona, M. (2007). Urban Design Reader. Amsterdam; Boston, MA: Routledge.

[16] Velibeyoglu, V. (1999). Urban Design in the Postmodern Context. Urban Design in the Postmodern Context Koray Velibeyoglu,PhD Candidate at: Izmir Institute of Technology. Adopted from: http://www.angelfire.com/ar/co
rei/Velibeyoglu_UD.pdf

[17] Eraydin, Z. (2007). Building A Legible City: How Far Planning Is Successful in Ankara. Phd Thesis. Middle East Technical University.

[18] Bracken, I. (1981). Urban Planning Methods: Research and policy analysis. Methuen \& co, NY.

[19] Elgendy, H. (2003). Development and Implementation of Planning Information Systems in collaborative spatial planning processes. Ph.D. Dissertation. Universität Fridericiana zu Karlsruhe.

[20] Trancik, R. (1986), Finding Lost Space: Theories of Urban Design, Van Nostrand Reinhold, New York.

[21] Lynch, K. (1984), Good City Form, MIT Press, Cambridge.

[22] Newman, P., Jennings, I., (2008). Cities as Sustainable Ecosystems: Principles and Practices. Island Press, Washington, DC.

[23] Tolley, R. (2003). Sustainable Transport: Planning for Walking and Cycling in Urban Environments, Woodhead, Cambridge.

[24] Agboola, O. P., M. H. Rasidi, I. B. Said, S. D. Zakka, and A.-W. Shuaibu. "Residents' Social Interactions in Market Square and Its Impact on Community Well-Being”. Journal of Contemporary Urban Affairs, vol. 2, no. 2, July 2018, pp. 24-32, doi:10.25034/ijcua.2018.3668

[25] Agboola, O. P., M. H. Rasidi, I. B. Said, S. D. Zakka, and A.-W. Shuaibu. "Residents' Social Interactions in Market Square and Its Impact on Community Well-Being". Journal of Contemporary Urban Affairs, vol. 2, no. 2, July 2018, pp. 24-32, DOI:10.25034/ijcua.2018.3668.

[26] Foued Benghadbane , Fatima Zohra Berkani (2017). Urban Projects to Prefigure the Sustainable City -- Case: The City of Ain Beida (Algeria). Civil Engineering and Architecture, 5(2), 52 - 60. DOI: 10.13189/cea.2017.050202.

[27] Healey, P. (1997). Collaborative Planning. Shaping Places in Fragmented Societies. Basingstoke: McMillan.

[28] Khalee, A (1998). The Communicative Planning and Evaluation. in Nathaniel Lichfield, era/., (eds.), Evaluation in Planning: Facing the Challenges in Complexity', Dordrecht: Kluwer Academic Publishers.

[29] Forester, J. (1993). Critical Theory, Public Policy and Planning. Toward a Critical Pragmatism New York: SUNY Press.

[30] Naouel Hanane Boudjabi , Foued Bouzahzah , Abdelouhab Bouchareb (2018). Urban Strategies for a Renewal of Algerian Cities: Constantine of Tomorrow. Civil Engineering and Architecture, 6(1), 18 - 24. DOI: 10.13189/cea.2018.060 102. 